\title{
ACCURACY OF ANN BASED DAY-AHEAD LOAD FORECASTING IN TURKISH POWER SYSTEM: DEGRADING AND IMPROVING FACTORS
}

\author{
Ö. Tanıdır* O.B. Tör ${ }^{\dagger}$
}

\begin{abstract}
This paper presents development of a day ahead load forecasting (DALF) model for Turkish power system with an artificial neural network (ANN). Effects of special holidays including national and religious days, and hourly random load deviations observed in Turkish power system due to significant arc furnace loads are discussed. Performance of the ANN is investigated in the sense of both DALF performance - in terms of both daily mean absolute percentage error (MAPE) and hourly absolute percentage error (APE) - and hourly secondary reserves required to ensure supply/demand adequacy of the system. The most sensitive cities to DALF in terms of daily city temperature forecasts are ranked in order to reduce the input of the developed ANN and thereby to improve execution of the model. Candidate cities are determined based on both their placement with respect to climatic zones of the country and their contribution to the system load during peak hours. The results show that, although a well-trained ANN could provide very satisfactory daily MAPEs at non-special days, such as $\sim 1 \%$, the hourly absolute percentage errors (APE) could be significant due to large random load disturbances, which necessitate special attention during the day ahead allocation of hourly secondary reserves. By limiting the temperature data set with major cities, the input of ANN reduces significantly while not disturbing the MAPEs. Main contributions of the study are; addressing both benefits of the prioritizing the cities in a power system in the sense of their temperature forecast effects on the DALF performance and assessing the performance of DALF in the sense of necessary amount of secondary reserves in power systems which include significant random load deviations (e.g., large arc furnace loads).
\end{abstract}

Key words: absolute percentage error, artificial neural networks, day ahead load forecasting, mean absolute percentage error, secondary reserve, sensitivity

Received: September 13, 2013

DOI: $10.14311 / \mathrm{NNW} .2015 .25 .023$

Revised and accepted: May 21, 2015

* Özgür Tanıdır, TUBITAK MAM Energy Institute, METU Campus, Ankara, Turkey, Tel: +90 312 2101054, E-mail: ozgur.tanidir@tubitak.gov.tr

†Osman Bülent Tör - Corresponding author, EPRA, Hacettepe Teknokent, Ankara, Turkey, Tel: +90 312 2992527, E-mail: osman.tor@epra.com.tr 


\section{Introduction}

Power system planning and operation introduce complex engineering problems which are dependent to many system and environment variables. The key point is maintaining supply demand balance in the system at all times. Therefore, demand information must be forecasted for different time frames to carry out required actions and planning processes that ensure steady power system balance. Day ahead load forecasting (DALF), which cannot be easily formulated due to the high level of nonlinearity and randomness encapsulated in the load forecasting, is among the most crucial problem in this area. Therefore, learning by example approaches like regression, artificial neural network (ANN), have been utilized to obtain solutions $[1,3,5,8,14]$.

Recently, the highest attention has been given to the ANN in solving DALF problem due to its function approximation performance and ease of use. There are several neural network types used in literature like recurrent networks [1, 14], Kohonen maps $[3,5]$ and back propagation networks $[7,8,10]$. Improved version of the ANN, such as adaptive wavelet neural network (AWNN) has also been developed and applied in short term load and price forecasting [15]. Moreover, anomalous loads like holidays and differences in load curves during week will drive researchers to the integrated complex neural network models $[7,10]$.

Demand forecast horizon is ranging from one hour to one week to comply with related accuracy criteria. Weekly forecasts $[6,9]$ give more flexibility to the operators in making unit commitment, security analysis, and fuel scheduling. Essentially, major drawback of the weekly forecast is the degradation in forecast accuracy. The balance between forecast accuracy and operational assistance capacity leads to 24 hours ahead forecasts commonly in the literature $[2,6,7,8,10,12]$.

As given in [11], one hour ahead forecasting approach leads to better accuracy in load forecasting due to both accurate temperature information and the strong correlation between the demand and temperature. Since the power system of a country is composed of several demand substations that are spread among the country, temperature forecast for system total demand forecast is challenging due to the fact that the temperature forecasts of the cities varies among the cities particularly in geographically large countries, like Turkey. This complicates the learning by example in the ANN methods. The availability of accurate day ahead forecast for each substation could be another concern. In this study, this concern is addressed by prioritizing the cities in the sense of their temperature forecast effects on the DALF performance. ANN based DALF is performed for the Turkish power system which has different climatic zones, and therefore temperature diversification among the cities is significant. Sensitivity of the DALF performance to the temperature forecasts of major cities is discussed. This is the first contribution of the study.

Secondary reserves are allocated in power systems to compensate for both errors in hourly average demand forecasts and the load deviations (i.e., ramps) that occur within the hours [4]. Although, the better hourly average demand forecast, the lesser secondary reserve allocation, random demand variations (e.g., arc furnace loads) in power systems can significantly affect the amount of secondary reserve requirements. This is challenging phenomenon in countries which are subjected to 
Tanıdır Ö., Tör O.B.: Accuracy of ANN based day-ahead load forecasting in...

significant amount of random demand variations, like Turkey. In such countries, performance of the DALF algorithms can negatively be affected due significant random demand variations. It is a challenge to decouple the negative effect of such random load deviations in assessing the performance of the DALF algorithms. The random load deviations existing in the power system could hinder to give a decision about whether the DALF algorithm should be improved further or not. This concern is addressed in this study by assessing the performance of the DALF algorithm in the sense of necessary amount of secondary reserves which include significant random load deviations due to arc furnace factories spread in Turkey. This is the second contribution of the study.

The paper is organized as follows, in Section 2 structure of ANN utilized in this study is presented and input data selection and processing algorithms are described. In addition, the effects and the results of special holidays in neural networks are discussed. In Section 3, the effects of temperature information in neural network training are assessed and an approach for selecting optimal temperature data set for enhancing load forecast quality is presented. Finally, conclusion drawn from the study is given in Section 4 .

\section{ANN structure and input data process}

\subsection{ANN structure}

There are several types and variations of neural networks in the literature that have been used for DALF purposes. Feed forward back propagation type is the most popular and effective one which is commonly preferred [12]. Therefore, a two layer feed forward back propagation network that is represented in Fig. 1 is selected in this study to perform DALF simulations with two years of historical data (between 2009 and 2010) of Turkish power system. Last 100 days of historical data is separated from training data set to fulfill testing purposes. Total number of neuron number is optimized considering the total number of inputs and outputs.

In order to evaluate the load forecasting performance of the ANN, four different performance criteria are utilized:

- MAPE (Mean Absolute Percentage Error),

- Maximum Daily MAPE,

- Maximum Daily APE,

- Maximum Daily Peak Load APE,

where

$$
\begin{gathered}
\mathrm{APE}=\frac{\mid \text { Load }_{\text {forecast }}-\text { Load }_{\text {actual }} \mid}{\operatorname{Load}_{\text {actual }}} 100 \%, \\
\mathrm{MAPE}=\frac{1}{N_{\mathrm{h}}} \sum_{N_{\mathrm{h}}} \mathrm{APE},
\end{gathered}
$$

where $N_{\mathrm{h}}$ is the number of hours forecasted (24 for day ahead forecast). 


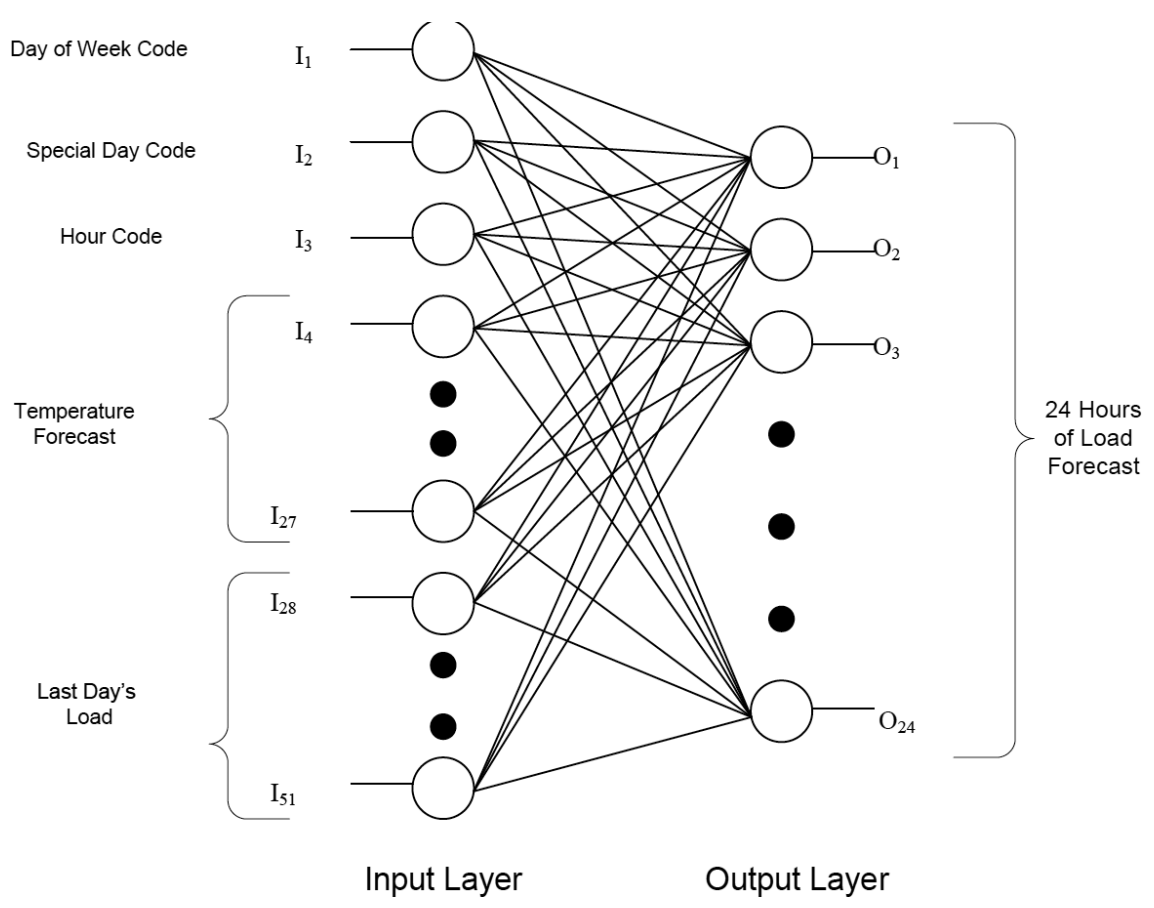

Fig. 1 Feed forward ANN structure that utilized in the analysis.

First two performance criteria defined above are utilized for evaluating network's fitting performance on target data (24 hour day ahead load) while the other two are utilized for evaluating network's fitting performance on daily load curves. The reason behind assessing different performance criterion is to prevent ANN from over fitting due to concentrating on a single performance criteria.

\subsection{Selection of input variables and training process}

As given in [2], there are several input parameters that are used in neural networks to achieve better load forecasting accuracy. However, there is no certain rule defined in selection and priority of input parameters as these parameters should be country specific. In order to ensure appropriate ANN architecture, 4 different ANN models are developed for Turkish power system in terms of total number and type of inputs, and total number of hidden layers as shown in Tab. I and II.

$L$ : Load; $d$ : Day; $h$ : Hour;

$S$ : Special day (religious and/or national holidays);

$T$ : Temperature of the major city in the sense of demand (i.e., Istanbul).

\subsection{Performance of the developed ANN in DALF}

The inputs and outputs of the ANN are normalized between $[-1,1]$ range to improve the performance. The performance analysis of the aforementioned ANN for 
Tanıdır Ö., Tör O.B.: Accuracy of ANN based day-ahead load forecasting in...

\begin{tabular}{|c|c|c|c|}
\hline ANN model & Neuron no & Inputs & Description \\
\hline \multirow{5}{*}{1} & \multirow{5}{*}{51} & 1 & Day of week code \\
\hline & & 2 & $\begin{array}{l}\text { Special day code } \\
(S(d-1)=1, S(d)=2, S(d+1)=3)\end{array}$ \\
\hline & & 3 & Hour Code \\
\hline & & $4-27$ & $\begin{array}{l}\text { Temperature forecast of Istanbul city } \\
(T(d, h), h=1, \ldots, 24)\end{array}$ \\
\hline & & $28-51$ & $\begin{array}{l}\text { Last day's load } \\
(L((d-1), h), h=1, \ldots, 24)\end{array}$ \\
\hline \multirow{6}{*}{2} & \multirow{6}{*}{75} & 1 & Day of week code \\
\hline & & 2 & $\begin{array}{l}\text { Special day code } \\
(S(d-1)=1, S(d)=2, S(d+1)=3)\end{array}$ \\
\hline & & 3 & Hour code \\
\hline & & $4-27$ & $\begin{array}{l}\text { Last day's temperature of Istanbul city } \\
(T((d-1), h), h=1, \ldots, 24)\end{array}$ \\
\hline & & $28-51$ & $\begin{array}{l}\text { Temperature forecast of Istanbul city } \\
(T(d, h), h=1, \ldots, 24)\end{array}$ \\
\hline & & $52-75$ & $\begin{array}{l}\text { Last day's load } \\
(L((d-1), h), h=1, \ldots, 24)\end{array}$ \\
\hline
\end{tabular}

Tab. I ANN models 1 and $2, d \pm i$ corresponds to the day before/after.

Turkish power system is given in Tab. III. As seen from the table, the highest performance is observed with the ANN Model 4 in which both realized and forecasted hourly temperatures of the major city, Istanbul, are included to the training set, in addition to historical load information. It is evident that the performance of the ANN model increases as the number of input variety increases preserving reliability of the data. The performance analysis given in Tab. III makes clear that adding last week's load values and last day's temperature values lead to better network performance in the sense of MAPE (see Tab. I and II). Given its highest performance, the ANN Model 4 is selected for further analysis.

Although the ANN methods give satisfactory results in general, the MAPE performance significantly reduces particularly during annual national and religious holidays in the country. The MAPE is observed to be as high as $20 \%$ during the religious holidays in Turkey. As seen from the Fig. 2, which describes daily MAPE values over the entire 2010, the model cannot generate accurate load forecasts during special holidays since the occurrence of such days are strictly limited in the two years historical data. This phenomenon clearly observed on the 100 days test data. On the other hand, weekend forecasts are acceptable given the two year training data set already includes sufficient weekend loading data. The MAPE of the ANN is around $1 \%$ during both weekdays and weekends as seen in Tab. II which shows one-year performance. 


\begin{tabular}{|c|c|c|c|}
\hline ANN model & Neuron no & Inputs & Description \\
\hline \multirow{6}{*}{3} & \multirow{6}{*}{75} & 1 & Day of week code \\
\hline & & 2 & $\begin{array}{l}\text { Special day code } \\
(S(d-1)=1, S(d)=2, S(d+1)=3)\end{array}$ \\
\hline & & 3 & Hour code \\
\hline & & $4-27$ & $\begin{array}{l}\text { Temperature forecast of Istanbul city } \\
(T(d, h), h=1, \ldots 24)\end{array}$ \\
\hline & & $28-51$ & $\begin{array}{l}\text { Last day's load } \\
(L((d-1), h), h=1, \ldots 24)\end{array}$ \\
\hline & & $52-75$ & $\begin{array}{l}\text { Last week's load } \\
(L((d-7), h), h=1, \ldots 24)\end{array}$ \\
\hline \multirow{7}{*}{4} & \multirow{7}{*}{99} & 1 & Day of week code \\
\hline & & 2 & $\begin{array}{l}\text { Special day code } \\
(S(d-1)=1, S(d)=2, S(d+1)=3)\end{array}$ \\
\hline & & 3 & Hour code \\
\hline & & $4-27$ & $\begin{array}{l}\text { Last day's temperature of Istanbul city } \\
(T((d-1), h), h=1, \ldots 24)\end{array}$ \\
\hline & & $28-51$ & $\begin{array}{l}\text { Temperature forecast of Istanbul city } \\
(T(d, h), h=1, \ldots 24)\end{array}$ \\
\hline & & $52-75$ & $\begin{array}{l}\text { Last day's load } \\
(L(d-1), h), h=1, \ldots 24)\end{array}$ \\
\hline & & $76-99$ & $\begin{array}{l}\text { Last week's load } \\
(L(d-7), h), h=1, \ldots 24)\end{array}$ \\
\hline
\end{tabular}

Tab. II ANN models 3 and $4, d \pm i$ corresponds to the day before/after.

\begin{tabular}{cc}
\hline ANN Model & $\begin{array}{c}\text { MAPE of the training set } \\
{[\%]}\end{array}$ \\
\hline 1 & 1.47 \\
2 & 1.26 \\
3 & 1.32 \\
4 & 1.15 \\
\hline
\end{tabular}

Tab. III Performance comparison of different ANN models.

\section{Ranking of major cities in terms of sensitivity of the system load to city temperature forecasts}

According to the results given in the previous section, it is observed that the temperature information along with the previous load data are the main factors 448 
Tanıdır Ö., Tör O.B.: Accuracy of ANN based day-ahead load forecasting in...

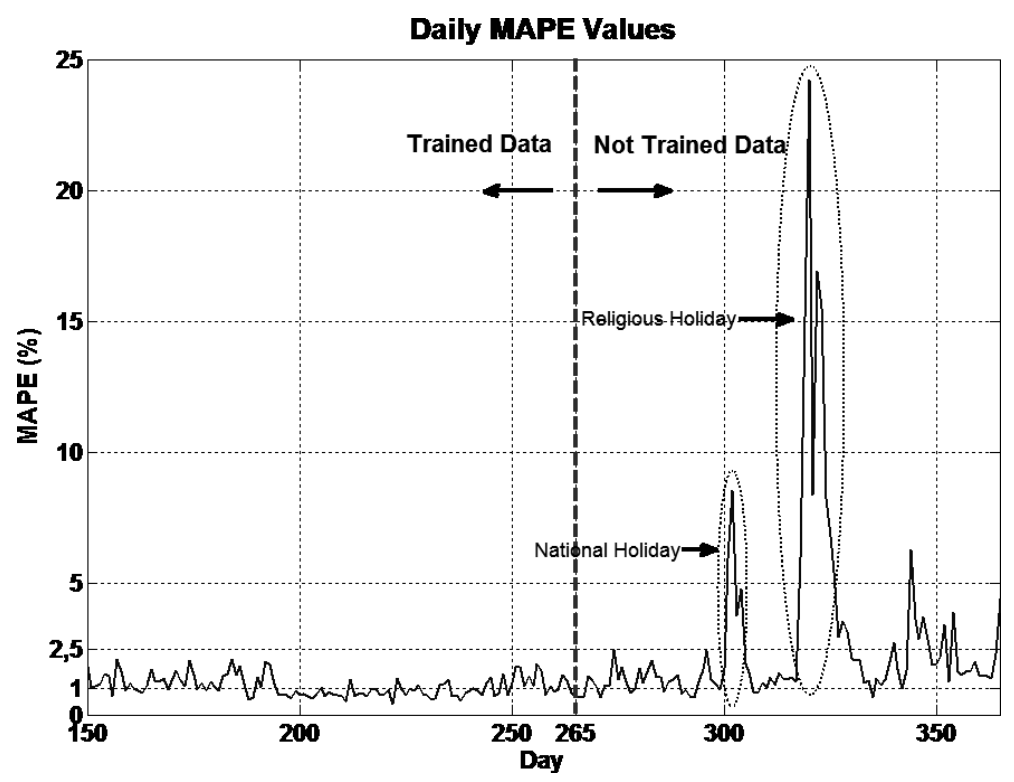

Fig. 2 Daily MAPE values.

that influence the load forecasts. However, utilization of the temperature forecasts of all cities within the country as an input to the ANN increases dimension of the ANN significantly, particularly for large countries that have various climatic zones, like Turkey. (The availability of accurate day ahead forecast for each demand substation can also be a concern.) This will essentially slow down the execution of the ANN during daily load forecasting. Therefore, selection of a considerable size of temperature data set (i.e., temperature set of cities on which system load is more sensitive), which describes the hourly load forecast of the power system under investigation is important.

In this section, ranking of the cities in Turkey in terms of the sensitivity of the total system hourly load to their temperature forecasts is analysed. For this aim, first, the cities in the country are ranked with respect to their share on the Turkish annual peak demand. Then, starting from the top of this rank, the cities that are placed at different climatic zones of the country are picked. Turkey is one of the countries that has different climatic zones as shown in Fig. 3. The cities which both contribute to the country annual peak demand most and placed at different climatic zones are given in the last raw of Tab. IV.

Performance of the ANN is analysed separately for all scenarios shown in Tab. IV in order to reveal the effect of increasing number of temperature inputs to the ANN. In order to better observe this, the test data is reduced to 30 days (unlike the training data set defined in Section 2 in which test data was 100 days). The reason for this reduction is to separate the negative effects of holidays that occurred during the last 100 days.

Performance result of each scenario is given in Tab. V (note that the Scenario 1 is the same as ANN Model 4 (see Tab. III) in which only temperature data set of 


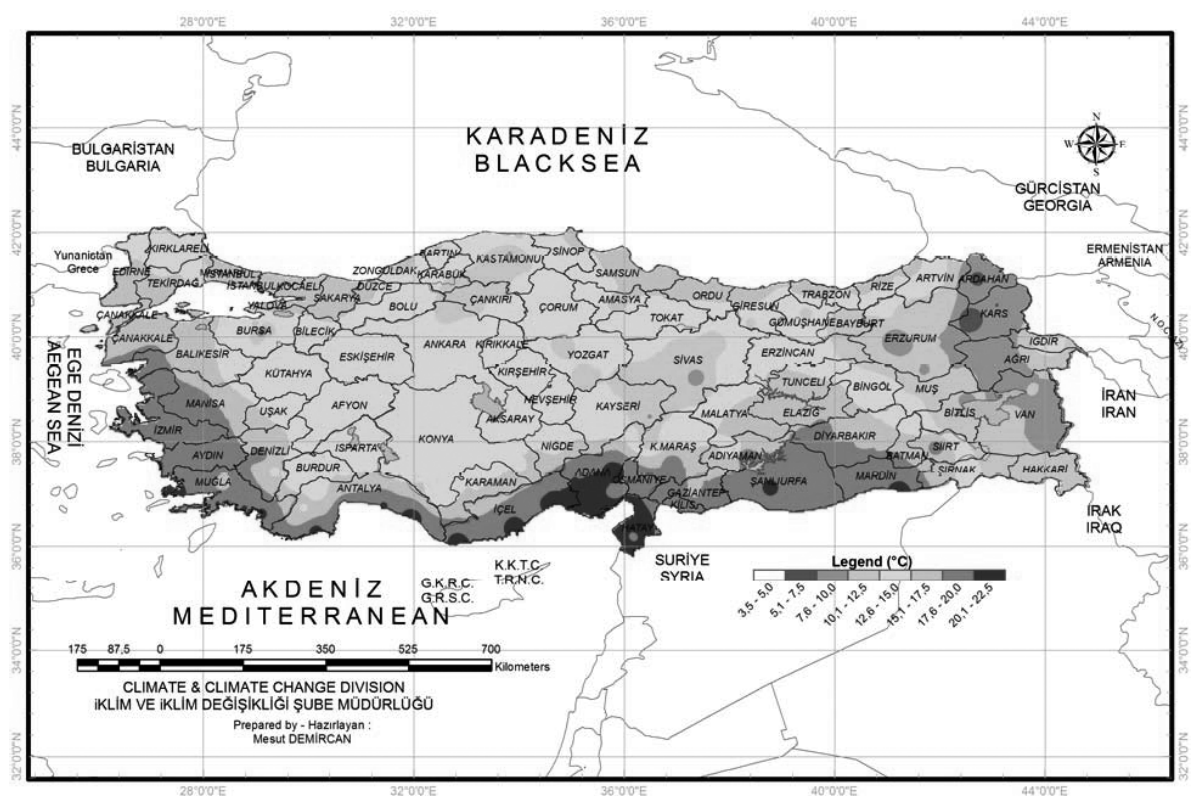

Fig. 3 Distribution of mean temperatures in Turkey (2010).

\begin{tabular}{clc}
\hline Scenarios & Input temperature & $\begin{array}{c}\text { Share on Turkish peak load } \\
{[\%]}\end{array}$ \\
\hline 1 & Istanbul & 17.77 \\
2 & Istanbul, Izmir & 25.91 \\
3 & Istanbul, Izmir, Ankara & 31.05 \\
4 & Istanbul, Izmir, Ankara, Bursa & 35.37 \\
\hline
\end{tabular}

Tab. IV Temperature data sets utilized in training.

Istanbul city - the largest metropolitan in Turkey - is taken into account). When the MAPEs of different scenarios are compared, it is observed that the inclusion of additional city temperature data to the ANN input improves the performance of the ANN. On the other hand, the improvement is saturated as the number of metropolitan cities increases further.

The developed ANN is trained continuously with the accumulated data. DALF results including before and after a special day (19 May 2012; national holiday) are given in Fig. 4, 5 and 6, along with the actual demands recorded. These figures verify success of DALF performance of the ANN in both special and non-special days. It is clear from the figures that the degradation in DALF performance in the special day recovers significantly in the day after. Performance of the DALF in special days is expected to be improved as the accumulation of input data in the future. 
Tanıdır Ö., Tör O.B.: Accuracy of ANN based day-ahead load forecasting in...

\begin{tabular}{cc}
\hline Scenarios & $\begin{array}{c}\text { MAPE of the training set } \\
{[\%]}\end{array}$ \\
\hline 1 & 1.15 \\
2 & 1.15 \\
3 & 1.09 \\
4 & 1.06 \\
\hline
\end{tabular}

Tab. V MAPE comparison of all scenarios (training data).

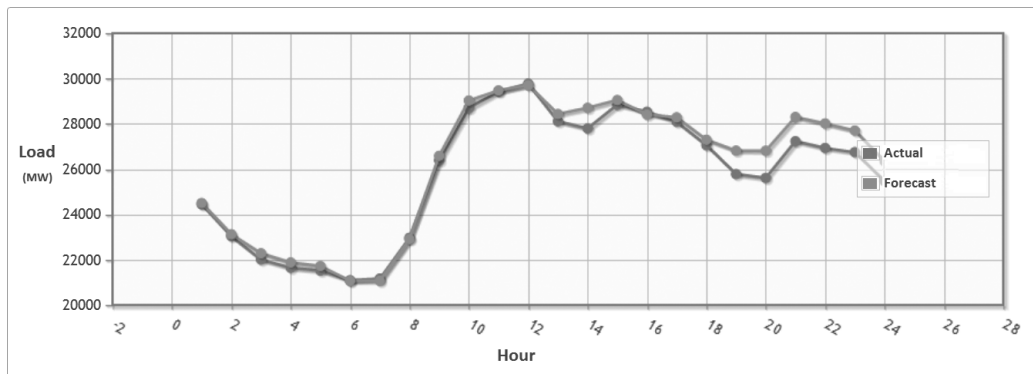

Fig. 4 DALF results on 18 May 2012 (day before the special day).

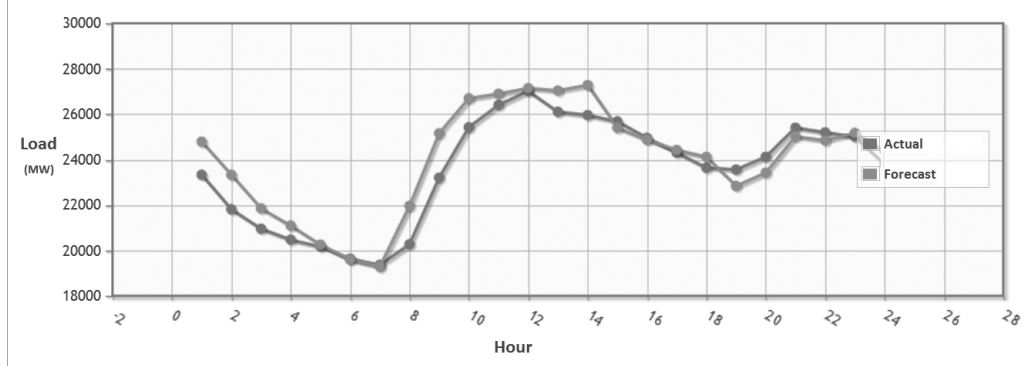

Fig. 5 DALF results on 19 May 2012 (special day: national holiday).

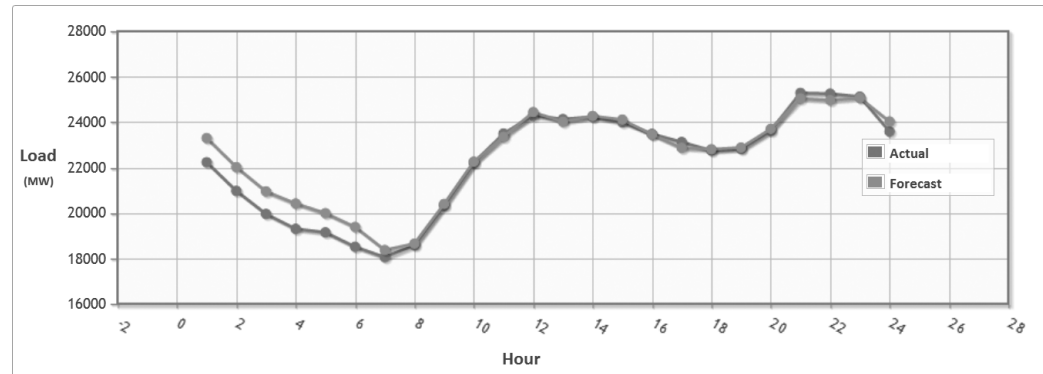

Fig. 6 DALF results on 20 May 2012 (day after the special day). 


\section{The effects of random load deviations on the performance of DALF}

Indeed, the insufficiency of historical special holiday load data is not the sole reason in getting poor performance values from the ANN. Great amount of random load deviations presents in Turkish power system due to large arc furnace factories. These arc furnaces, which consume more than hundreds of MWs during melting process, are widely distributed in the country and operating randomly. This phenomenon is illustrated in Fig. 7 which shows power steps during switching on and off of an arc furnace in Turkey. Therefore, it is common to have random sharp load increment or decrement in the system load.

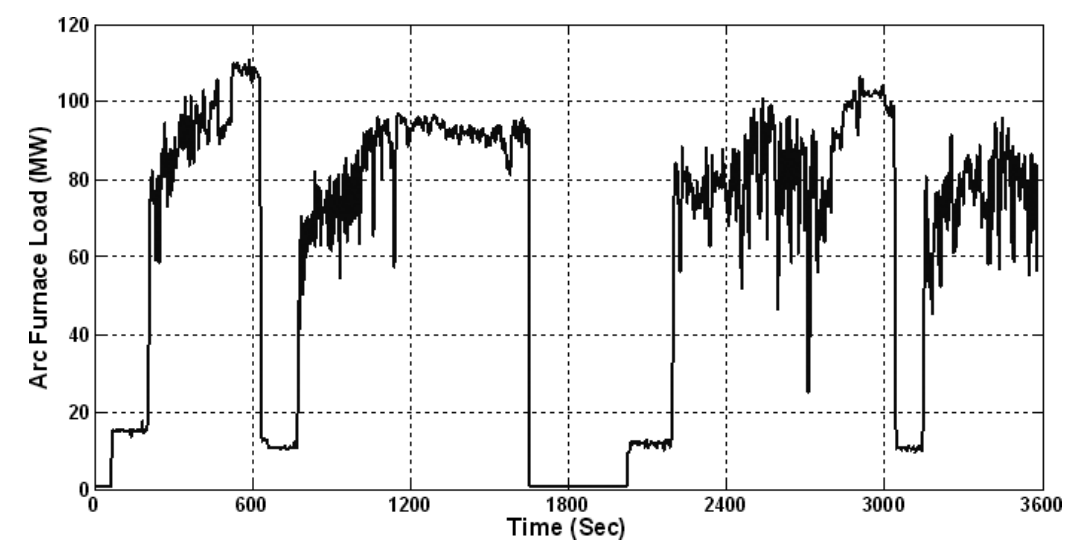

Fig. 7 Power steps during switching on and off of an arc furnace (taken from a factory in Turkey).

Amount of the power that reflected on the interconnection lines essentially increases if the arc furnaces located at different parts of the country coincide. In Turkey, total power step amount up to $\approx 900 \mathrm{MW}$ within $\approx 5$ minutes is observed due to arc furnaces as illustrated in Fig. 8 (pink curve). As seen in the figure, the available secondary reserve (blue curve) drastically reduces to compensate the ACE which is deviated due to power mismatches on the interconnected lines during the fast load changes. This curve illustrates the correlation between the required amount of secondary reserves and random large load changes as well.

This phenomenon disturbs the ANN training process in both working days and holidays. As shown in Fig. 9, the daily curve of the actual load (given in dashed line) is much smoother in holidays than that of normal working days as the steel factories are working less in holidays than working days (see the black rectangle in Fig. 9).

In conclusion, although during non-special holidays the ANN gives quite satisfactory MAPE values, hourly load forecast errors (APEs) are significant during some hours due to the random load deviations. An example of this situation is shown in Tab. VI and Fig. 10. 
Tanıdır Ö., Tör O.B.: Accuracy of ANN based day-ahead load forecasting in...

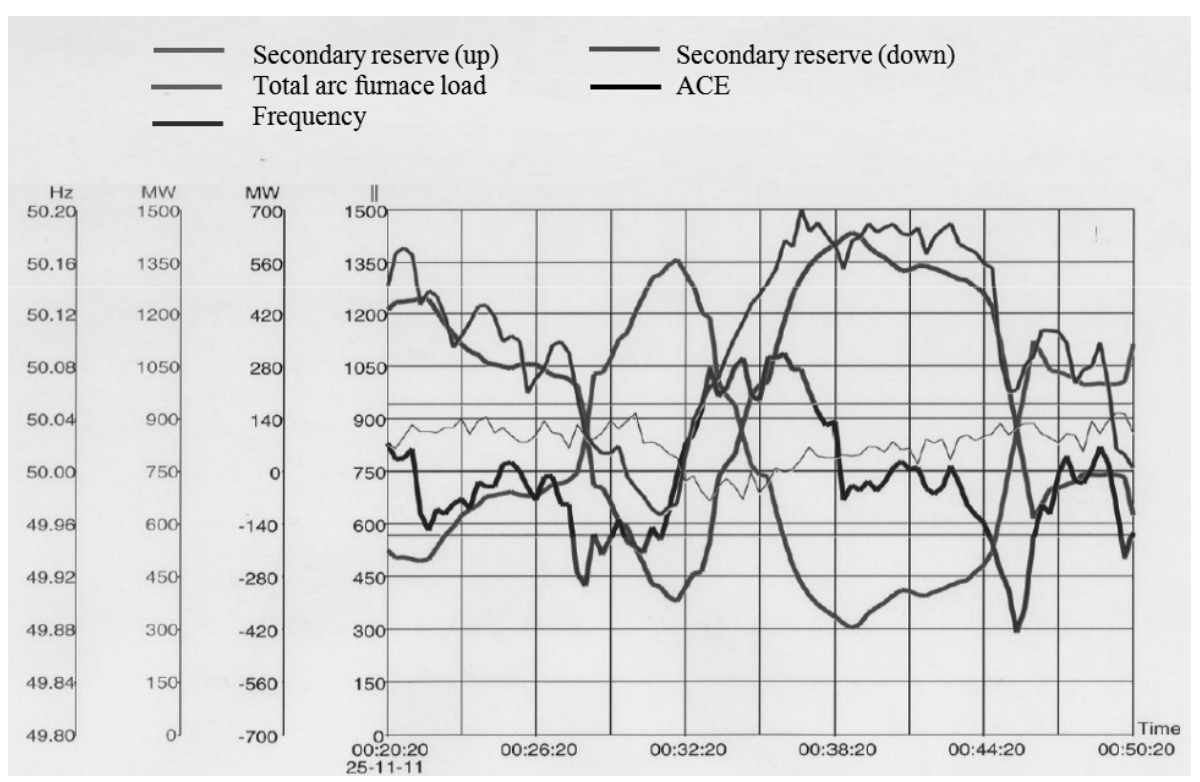

Fig. 8 SCADA measurements taken from Turkish grid (the effect of arc furnace on the $A C E)$.

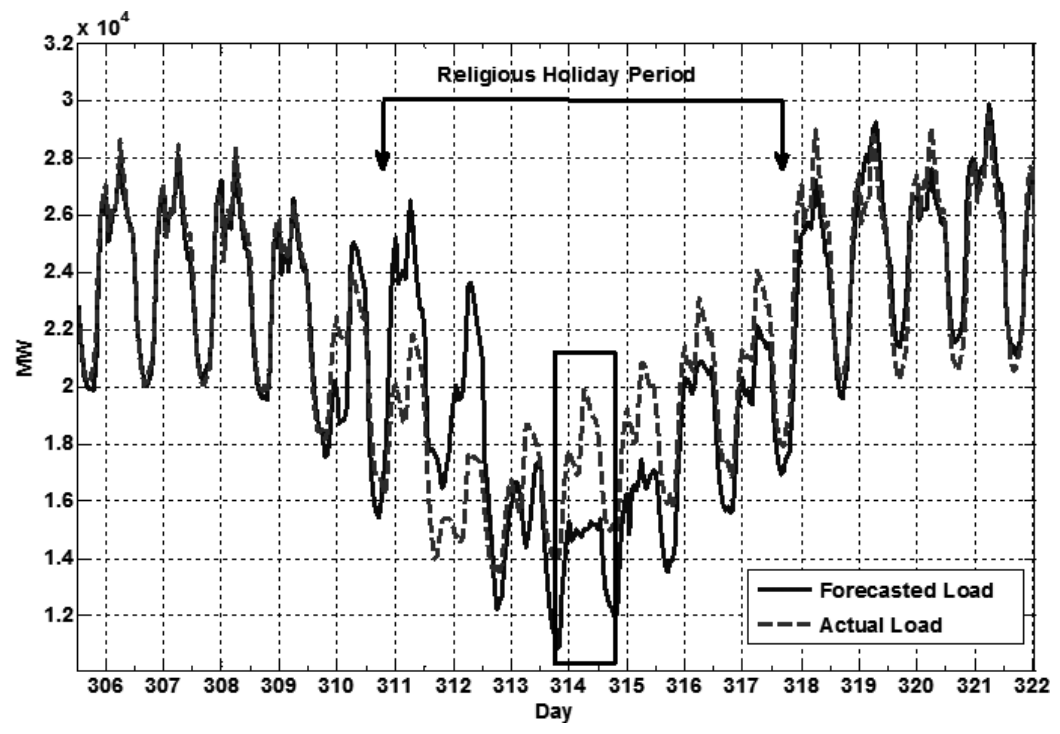

Fig. 9 Forecast accuracy degradation in special holidays.

As seen from Tab. VI, although the MAPE for 24 hour load forecast is lower than 1\%, there is an hour (13:00 i.e., 01:00 pm) when the maximum APE is above 4\%. At that hour, this significant error in APE would result in utilization of secondary reserves that is available to compensate the generation/load imbalance 


\begin{tabular}{cc}
\hline $\begin{array}{c}\text { MAPE of the day } \\
{[\%]}\end{array}$ & $\begin{array}{c}\text { Maximum APE along the day } \\
{[\%]}\end{array}$ \\
\hline 0.73 & 4.34 \\
\hline
\end{tabular}

Tab. VI ANN performance indices on January 8, 2010.

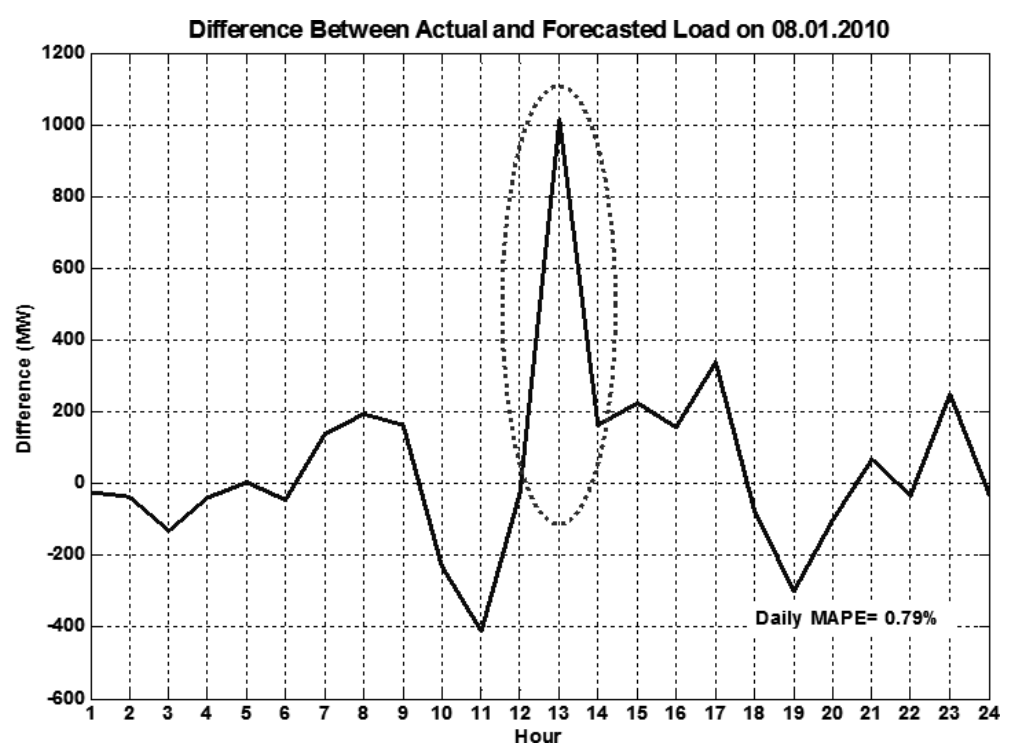

Fig. 10 Hourly forecast error of a day.

in the power system. For a $30000 \mathrm{MW}$ peak load, this corresponds to almost $4 \%$ $\times 30000=1200 \mathrm{MW}$, which is a significant value.

It should be emphasized that, from the day ahead generation planning point of view, the hourly load forecast errors may lead significant load generation imbalance which should be compensated by the available secondary reserve on the power system. In other words, to be on the safe side, the hourly load forecast errors of the ANN should be lower than the total secondary reserve available in the system (ignoring uncertainties in generations). Otherwise, either the insufficient secondary reserves will be compensated by the neighbour interconnected power systems, or the frequency deviation of the system will increase during these hours which may result in load shedding by means of low frequency load shedding relays. Given the complexity of management, secondary reserves are generally allocated fixed amounts for several hours rather than hourly allocation [13]. For example, secondary reserves are allocated twice a day (day and night) in Turkey. On the other hand, given the fact that the high APE values are connected with the random loads particularly due to arc furnaces in Turkey, such forecasting errors during some hours cannot be mitigated by the ANN that is trained under the scope of minimizing the total MAPE. 
Tab. VII compares different ANN performance criterion. As seen from Tab. VII, although the MAPE of the training set is around $1 \%$ in both Scenario 1 (only temperature data of Istanbul city is considered in the ANN) and Scenario 4 (temperature data of major cities are considered in the ANN), the maximum APEs within the day are significantly above the average due to random loading effects of arc furnaces. On the other hand, the maximum APE values are very close in both scenarios. That is, although performance of the ANN in Scenario 4 is better than that of Scenario 1, this does not make sense in terms of the amount of allocated secondary reserve amount which is fixed for several hours. In other words, the improvements in the daily MAPE by including more city temperatures as an input to the ANN does not make sense from the viewpoint of secondary reserves allocation which is connected with the maximum APE. In conclusion, given the significant random load disturbances, considering hourly temperature forecasts of only four major cities in Turkish power system is sufficient.

\begin{tabular}{cccc}
\hline \multirow{2}{*}{ Scenario } & \multirow{2}{*}{ Training set MAPE [\%] } & \multicolumn{2}{l}{ Maximum daily test set [\%] } \\
\cline { 3 - 4 } & & MAPE & APE \\
\hline 1 & 1.15 & 2.44 & 6.33 \\
4 & 1.06 & 2.45 & 5.99 \\
\hline
\end{tabular}

Tab. VII MAPE comparison of Scenarios 1 and 4 (test and training data).

\section{Conclusion}

In this study, ANN based DALF for Turkish power system is discussed. The results show that special holidays (national and religious days) and random load deviations due to arc furnaces have significant negative effect on the load forecasting performance of the ANN in the sense of APE performance. Although the ANN's performance during non-special days including both weekdays and weekends is satisfactory from daily MAPE point of view, the hourly APEs along the day could be significant due to this random load effects.

Although the inclusion of more city temperature data to the ANN input improves the MAPE performance of the ANN, the improvement is saturated as the number of cities increased. Main advantage of the proposed technique is that further increase of ANN input dimension is not necessary to forecast sufficient amount of secondary reserves in power systems, which include significant random disturbance loads, like Turkey. However, as a common problem of ANN techniques, forecasting the demand at special days still needs improvement.

Future studies may include training the ANN model without special days and holidays and develop a special model for such days. Clustering the available temperature time series and using the cluster centres as ANN inputs is also a promising follow up study. 


\section{Acknowledgement}

This work was supported in part by Turkish Electricity Transmission Company (TEIAŞ) and Küçük ve Orta Ölçekli İşletmeleri Geliştirme ve Destekleme İdaresi Başkanlığı (KOSGEB).

\section{References}

[1] CZERNICHOW T., DORIZZI B., CAIRE P. Load Forecasting and Recurrent Networks. Neural Network World. 1993, 6, pp. 895-905.

[2] DREZGA I., RAHMAN S. Input Variable Selection for Ann-Based Short-Term Load Forecasting. IEEE Transactions on Power Systems. 1998, 13(4), pp. 1238-1244, doi: $10.1109 / 59.736244$.

[3] HSU Y.Y. Design of Artificial Neural Networks for Short Term Load Forecasting. Part I: Self Organizing Feature Maps for Day Type Identification. IEEE Proceedings- $C$ (Generation, Transmission and Distribution). 1991, 138(5), pp. 407-413, doi: 10.1049/ip-c.1991.0051.

[4] JALEELI N., VANSLYCK, LOUIS S., EWART D.N., FINK L.H., HOFFMANN A.G. Understanding Automatic Generation Control. IEEE Transactions on Power Systems. 1992, 7(3), pp. 1106-1122, doi: 10.1109/59.207324.

[5] KHADEM M. Application of the Kohonen Neural Network Classifier to Short-term Load Forecasting. Panel Session on Application of Neural Networks to Short-term Load Forecasting, IEEE PSWM Winter Meeting, Columbus, Ohio. 1993, pp. 407-412.

[6] KIARTZIS S.J., ZOUMAS C.E., THEOCHARIS J.B. BAKIRTZIS A.G. PETRIDIS V. Short-term Load Forecasting in an Autonomous Power System Using Artificial Neural Networks. IEEE Transactions on Power Systems. 1997, 12(4), pp. 1591-1596, doi: $10.1109 / 59.627863$

[7] LAMEDiCA R., PRUDENZI A., SFORNA M., CACIOTTA M., CENCELLI V.O. A Neural Network Based Technique For Short-Term Forecasting of Anomalous Load Periods. IEEE Transactions on Power Systems. 1996, 11(4), pp. 1749-1756, doi: 10.1109/59.544638.

[8] PARK D.C., EL-SHARKAWI M.A., MARKS R.J. Electric Load Forecasting Using an Artificial Neural Network. IEEE Transactions on Power Systems. 1991, 6(2), pp. 442-449, doi: $10.1109 / 59.76685$.

[9] PENG T.M., HUBELE N.F., KARADY G.G. An Adaptive Neural Network Approach to One-Week ahead Load Forecasting. IEEE Transactions on Power Systems. 1993, 8(3), pp. 1195-1203, doi: 10.1109/59.260877.

[10] PIRAS A., GERMOND A., BUCHENEL B., IMHOF K., JACCARD Y. Heterogeneous Artificial Neural Network for Short Term Electrical Load Forecasting. IEEE Transactions on Power Systems. 1996, 11(1), pp. 397-402, doi: 10.1109/59.486124.

[11] SENJYU T., TAKARA H., UEZATO K., FUNABASHI T. One-Hour-Ahead Load Forecasting Using Neural Network. IEEE Transactions on Power Systems. 2002, 17(1), pp. 113-118, doi: $10.1109 / 59.982201$.

[12] SHAHIDEHPOUR M., YAMIN H., LI Z. Market Operations in Electric Power Systems: Forecasting, Scheduling, and Risk Management. 1st ed. Wiley, John \& Sons, Inc., 2002, doi: 10.1002/047122412x.

[13] TOR O.B., GenCOGLU C., YILMAZ O., CEBECI E., GUVEN, A.N. Damping Measures against Prospective Oscillations between Turkish Grid and ENTSO-E CESA System. International Conference on Power System Technology (POWERCON 2010), Hangzhou, China. IEEE, 2010, doi: 10.1109/POWERCON.2010.5666448.

[14] VERMAAK J. Recurrent Neural Networks for Short-Term Load Forecasting. IEEE Transactions on Power Systems. 1998, 13(1), pp. 126-132, doi: 10.1109/59.651623.

[15] WU L., SHAHIDEHPOUR M. A Hybrid Model for Day-Ahead Price Forecasting. IEEE Transactions on Power Systems. 2010, 25(3), pp. 1519-1530, doi: 10.1109/tpwrs.2009.2039948. 